\title{
Bilirubin Metabolism in the Fetus *
}

\author{
Steven Schenker, $\dagger$ Nancy H. Dawber, and Rudi Schmid \\ (From the Thorndike Memorial Laboratory and the Second and Fourth [Harvard] Medicai \\ Services, Boston City Hospital, and the Department of Medicine, Harvard Medical
}

School, Boston, Mass.)

Although the kinetics of fetal erythropoiesis and the life span of fetal erythrocytes have not been accurately determined, thus precluding a quantitative appraisal of bilirubin production in the fetus, there is convincing evidence that this pigment is formed during intrauterine life. Supporting this are the presence of bilirubin in meconium (2), in fetal plasma (3) and the fetal gall bladder (4), and the elevated mean bilirubin concentrations in fetal and cord blood as compared to those in maternal blood $(3,5)$. On the other hand, in fetal liver the enzymatic apparatus for glucuronide formation is functionally deficient (6), which is believed to interfere with pigment excretion in the fetal bile (7). Despite this "immaturity" of the fetal liver, bilirubin levels in cord blood are surprisingly low (8), even in instances of erythroblastosis in which manifest hemolysis had occurred in utero (9). Shortly after birth, however, the level of unconjugated bilirubin in the neonatal serum rises steeply, reaching peak values during the first week of life (8). These observations suggest that during intrauterine life fetal bile pigment is disposed of by mechanisms other than biliary excretion, and they point to the placenta as a likely route of elimination (10).

Previous investigations found human and rat placenta to lack the enzymatic mechanism for glucuronide formation (10), indicating that in fetal bile pigment metabolism, the placenta does

\footnotetext{
* Submitted for publication June 19, 1963; accepted September 19, 1963.

Presented in part at the thirty-fifth meeting of the Central Society for Clinical Research, Chicago, Ill., November 2, 1962 (1). Supported in part by U. S. Public Health Service grant A-1833.

$\dagger$ Postdoctoral research fellow, National Institutes of Health, Bethesda, Md.; John and Mary R. Markle Scholar in Academic Medicine. Present address: Department of Medicine, University of Cincinnati Medical College, Cincinnati, Ohio.
}

not simply assume the role played by the liver in postnatal life. Indirect evidence for passage of bilirubin from the fetal to the maternal circulation has been sought by comparing pigment levels in arterial and venous cord blood (11-13) and in fetal, maternal, and retroplacental blood (5), but in most instances the observed differences were so small that interpretation was difficult. In pregnant guinea pigs, direct perfusion of the placenta with unconjugated bilirubin administered through the umbilical artery resulted in its rapid transfer to the maternal circulation (10), but this system was unphysiologic because of the infusion of high initial pigment concentrations and the exclusion of the fetal circulation.

The availability of bilirubin- $\mathrm{C}^{14}$ (14) has made possible a new approach to this problem. In preliminary experiments with the fetus excluded from the placental circulation, radioactive bilirubin or albumin- $\mathrm{I}^{131}$ was injected into an umbilical artery for direct perfusion of the placenta. This experimental procedure resulted, however, in gross discoloration and edema of the placenta, suggesting acute tissue injury. Moreover, in addition to rapid transfer of both unconjugated and conjugated bilirubin- $\mathrm{C}^{14}$, albumin- $\mathrm{I}^{131}$ passed the placenta at a much higher rate than would have been expected on the basis of current concepts $(15,16)$. Since these observations suggested that interruption of the fetal circulation may artificially alter placental permeability, an experimental approach more closely resembling physiologic conditions was designed.

With appropriate surgical techniques, it was possible to obtain and maintain viable guinea pig fetuses with intact placental circulation. Unconjugated or conjugated bilirubin- $\mathrm{C}^{14}$ was then injected into the fetal circulation via the umbilical vein for determination of pigment disappearance from the fetal circulation and of pigment excretion in maternal and fetal bile. 


\section{FETUS PLACENTA MATERNAL LIVER}

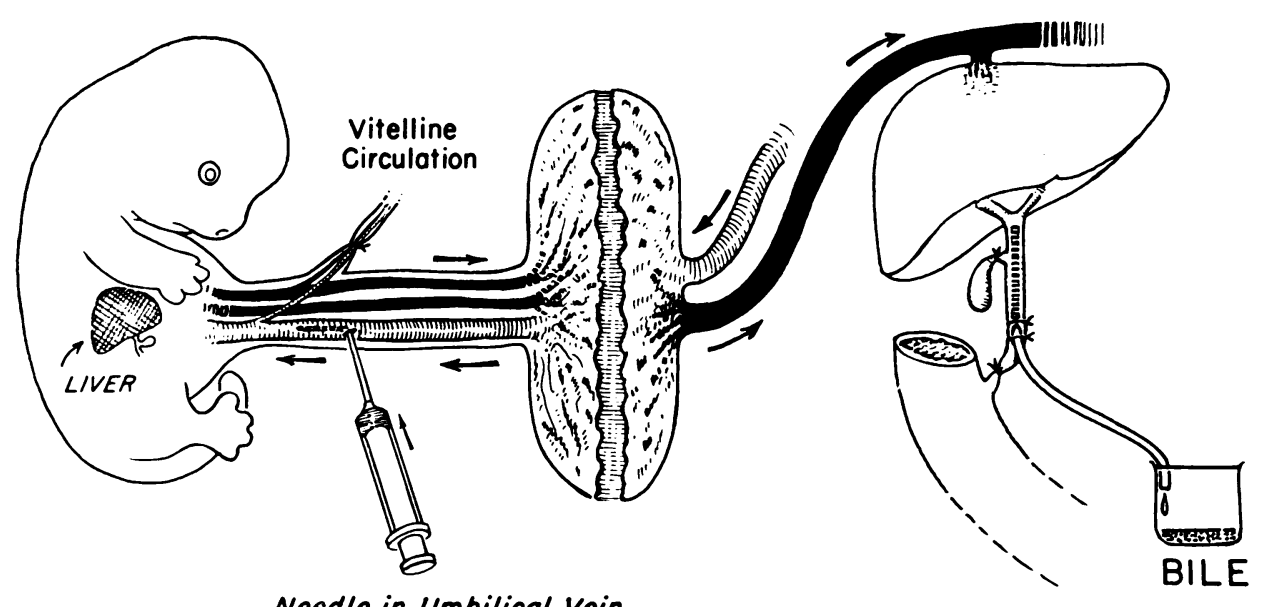

Needle in Umbilical Vein

Fig. 1. Diagram of the experimental Setup. Fetus, placenta, and uterus were submerged in isotonic saline at $37^{\circ} \mathrm{C}$. For injection into the umbilical vein, a loop of the umbilical cord was transiently brought above the surface of the saline bath.

\section{Materials and Methods}

Unconjugated crystalline bilirubin- $\mathrm{C}^{\mathbf{1 4}}$ was prepared biosynthetically (14) and after recrystallization was stored in a light-protected desiccator over paraffin shavings and $\mathrm{CaSO}_{4}$. For iv administration, 100 to $700 \mu \mathrm{g}$ of the crystalline pigment ( $\mathrm{SA}, 24$ to $940 \mathrm{dpm}$ per $\mu \mathrm{g}$ ) was dissolved in 0.1 to $0.2 \mathrm{ml}$ of cold $0.1 \mathrm{~N} \mathrm{NaOH}$ and rapidly added to 2 or $3 \mathrm{ml}$ of adult or fetal guinea pig serum. Conjugated bilirubin- $\mathrm{C}^{14}$ was prepared by infusing unconjugated labeled pigment into guinea pigs or rats with an external biliary fistula. During the ensuing 3 hours, virtually all injected label was excreted in the bile as conjugated bilirubin- $\mathrm{C}^{14}$. The bile specimens were collected in the dark at $4^{\circ} \mathrm{C}$ and stored at $-30^{\circ} \mathrm{C}$ for 1 to 3 hours before use. For iv administration, samples of these bile specimens containing measured amounts (17) of conjugated bilirubin- $\mathrm{C}^{14}$ were used.

Preparation of the experimental animals and administration of radioactive pigments. Pregnant guinea pigs within an estimated 2 weeks of delivery (gestational period, 65 days) were used. Anesthesia was induced by intraperitoneal administration of $6 \mathrm{mg}$ pentobarbital and was maintained by intermittent inhalation of ethyl ether. Through a small midline epigastric incision, the distal end of the common bile duct was ligated, and a PE-50 polyethylene catheter ${ }^{1}$ was inserted into the proximal portion and secured with a ligature. The cystic duct was ligated, and the content of the gall bladder was aspirated. The polyethylene catheter was brought to the outside to permit free drainage of the bile into light-protected, icecooled test tubes. The guinea pig was then submerged to

\footnotetext{
${ }^{1}$ Clay-Adams, Inc., New York 10, N. Y.
}

the neck in an isotonic saline bath at $37^{\circ} \mathrm{C}$ and strapped in a semirecumbent position permitting unrestricted respiration. After the abdominal incision had been extended to just above the pubis, the uterus was extruded from the submerged pelvis, opened along its relatively avascular margin, and a fetus delivered into the bath. The amnion was stripped from the fetus and umbilical cord, and the submerged fetus was loosely secured to the wall of the bath vessel with silk ties. The remaining fetuses were left in situ in the submerged uterus.

The vitelline circulation, which does not function in primates (18), was tied off by a ligature placed close to its point of origin on the umbilical cord. The radioactive pigments were injected through a 27 -gauge needle into the umbilical vein in the direction of the fetus (Figure 1). The total volume injected ranged from 1 to 2 $\mathrm{ml}$, administered over the course of 2 minutes. In some of the animals studied, a loose silk loop was placed around the umbilical vein on the maternal side of the site of injection to permit transient occlusion of the vessel during the period of injection.

After withdrawal of the needle and temporary application of gentle pressure to the site of injection to prevent leakage of blood, the maternal-fetal circulation remained functional and the submerged fetus viable for at least 2 hours.

Viability was monitored by palpation of the fetal heart rate, which did not slow in the course of the experiments. In guinea pigs close to term, the fetuses often remained viable, after separation from the mother, at the end of a 2-hour experiment. Liver tissue of three fetuses sacrificed at the end of the study was prepared for histologic examination. 
Placental transfer of bilirubin- $C^{14}$ and of albumin- $I^{131}$. Since bilirubin is rapidly cleared from the maternal circulation, pigment transfer across the placenta can be calculated from the excretory rate of bilirubin- $\mathrm{C}^{14}$ in maternal bile. Therefore, for a period of 2 hours after infusion of labeled pigment into the fetal circulation, maternal bile was collected every 15 minutes for determination of bilirubin concentration (17) and total radioactivity (14). After addition of appropriate amounts of conjugated bilirubin as unlabeled carrier, bilirubin from all bile specimens was crystallized (14) for determination of specific activity. Toluene- $\mathrm{C}^{14}$ was used as an internal standard, and radioactivity was expressed in dpm (14). Total excretion of bilirubin- $C^{14}$ was calculated from the volume of the bile specimens, the pigment concentration, and the specific activity of the bilirubin crystals.

In seven instances, the fetus was injected with 3 to $42 \mathrm{mg}$ of human albumin- $\mathrm{I}^{131} 2$ or with 1.8 to $5.9 \mathrm{mg}$ guinea pig albumin- ${ }^{131}$ [Cohn and associates' fraction $\mathrm{V}(19)^{3}$ ]. Placental transfer of albumin was estimated by determining the trichloroacetic acid-precipitable radioactivity in maternal plasma samples collected after 30 , 60 , and 120 minutes. Plasma volume of four pregnant guinea pigs was measured with iodinated guinea pig albumin (20). In two experiments in which the fetus was simultaneously injected with bilirubin- $\mathrm{C}^{\mathbf{1 4}}$ and albumin- $\mathrm{I}^{131}$, the bilirubin crystals prepared from the maternal bile were assayed in a well counter to ascertain absence of contaminating $\mathrm{I}^{131}$-activity.

Disappearance of bilirubin from the fetal circulation. Since after intrafetal injection of albumin- $\mathrm{I}^{131}$ virtually no placental transfer of the protein could be demonstrated, it was used for estimating fetal plasma volume. In sixteen fetuses ranging in weight from 31.8 to $78.3 \mathrm{~g}$

TABLE I

Transfer of unconjugated bilirubin- $C^{14}$ across the placenta, as measured by excretion of radioactive bilirubin in maternal bile

\begin{tabular}{clc}
\hline \hline & \multicolumn{2}{c}{$\begin{array}{c}\text { Recovery of radioactivity in } \\
\text { maternal bile in 2 hours } \\
\text { (expressed as \%o of ad- } \\
\text { ministered dose) }\end{array}$} \\
\cline { 2 - 2 } $\begin{array}{c}\text { Bilirubin-C14 } \\
\text { given per } \\
\text { fetal weight }\end{array}$ & In whole bile & $\begin{array}{c}\text { In crystallized } \\
\text { bilirubin }\end{array}$ \\
\hline$\mu g / g$ & & \\
0.8 & & $27.6(60 \mathrm{~min})$ \\
1.3 & 52.7 & 28.2 \\
$2.4 *$ & 54.8 & 55.4 \\
4.1 & & $35.4(60 \mathrm{~min})$ \\
7.2 & $18.8(40 \mathrm{~min})$ & 62.6 \\
9.9 & 66.0 & 22.3 \\
12.7 & 51.9 & 46.4 \\
13.2 & 58.0 & 43.0 \\
Mean & 56.7 & \\
\hline
\end{tabular}

* Bilirubin-C ${ }^{14}$ dissolved in fetal serum.

2 Abbott Laboratories, Inc., Oak Ridge, Tenn. SA, 13.8 $\mu \mathrm{c}$ per mg.

3 Pentex Corp., Kankakee, Ill. SA, $88 \mu \mathrm{c}$ per mg. (average, $50.1 \mathrm{~g}$ ), $3 \mathrm{mg}$ of human albumin- $\mathrm{I}^{131}$ in $0.3 \mathrm{ml}$ saline was administered via the umbilical vein. After 10 minutes fetal heart blood was obtained for determination of $\mathrm{I}^{131}$-activity and calculation of plasma volume (20). In six instances the amount of plasma trapped in the placenta was estimated by counting a homogenized sample of placental tissue in a well counter. Serum obtained from eight fetuses failed to exhibit measurable bilirubin concentrations.

Nineteen fetuses with intact placental circulation ranging in weight from 20 to $119 \mathrm{~g}$ (exclusive of placental weight) were injected with 2.4 to $17.1 \mu \mathrm{g}$ (average, $9.4 \mu \mathrm{g}$ ) of unconjugated or conjugated bilirubin per $g$ fetal weight. Bilirubin concentration after mixing in the circulation was calculated on the basis of fetal plasma volume plus injected volume, without correcting for distribution of pigment in extravascular spaces. After 10 to $120 \mathrm{~min}$ utes, individual fetuses were sacrificed for determination of serum radioactivity and bilirubin concentration (14, 17). Disappearance of the injected pigment was expressed as the residual amount of bilirubin in the fetal plasma as a percentage of the initial circulating amount. Removal of pigment from the circulation reflected not only placental transfer but also equilibration between the vascular and the extravascular spaces.

Pigment distribution in fetal tissues and excreta. Residual $\mathrm{C}^{14}$-activity in the placenta and in fetal serum, bladder urine, liver, kidneys, brain, and adipose tissue was determined (21) 2 hours after the iv injection of labeled bilirubin. The amount of pigment excreted in the fetal bile during this 2 -hour period was estimated by assaying the combined $\mathrm{C}^{14}$-activity in the contents of the fetal gall bladder, stomach, and intestinal tract. For assay of tissue radioactivity, portions were homogenized in $1 \mathrm{~N}$ $\mathrm{NaOH}$, boiled for 1 hour, and mixed with $\frac{1}{4}$ vol of methanol. After centrifugation, $0.05 \mathrm{ml}$ of the clear supernatant was used for determination of $\mathrm{C}^{14}$-activity in a Tri-Carb liquid scintillation spectrometer (14). Recovery experiments with this technique, carried out by homogenizing known quantities of bilirubin- $\mathrm{C}^{\mathbf{1 4}}$ with fetal guinea pig brain, yielded 84.5 and $85 \%$ of the added radioactivity (22).

Ancillary studies. Placental transfer of bilirubin from the maternal to the fetal circulation was studied in two animals. Ten and $40 \mathrm{mg}$ of unconjugated bilirubin dissolved in guinea pig serum were injected intravenously into two pregnant guinea pigs close to term, and from 5 to 9 minutes thereafter, fetal blood was obtained by cardiac puncture for determination of bilirubin concentration (17). In one of these experiments, vitelline vessels had been ligated before the administration of the pigment.

\section{Results}

Infusion of unconjugated bilirubin- $C^{14}$ into the fetus. The results of eight experiments in which unconjugated bilirubin- $\mathrm{C}^{14}$ was infused into living fetal guinea pigs are given in Table I. In all in- 


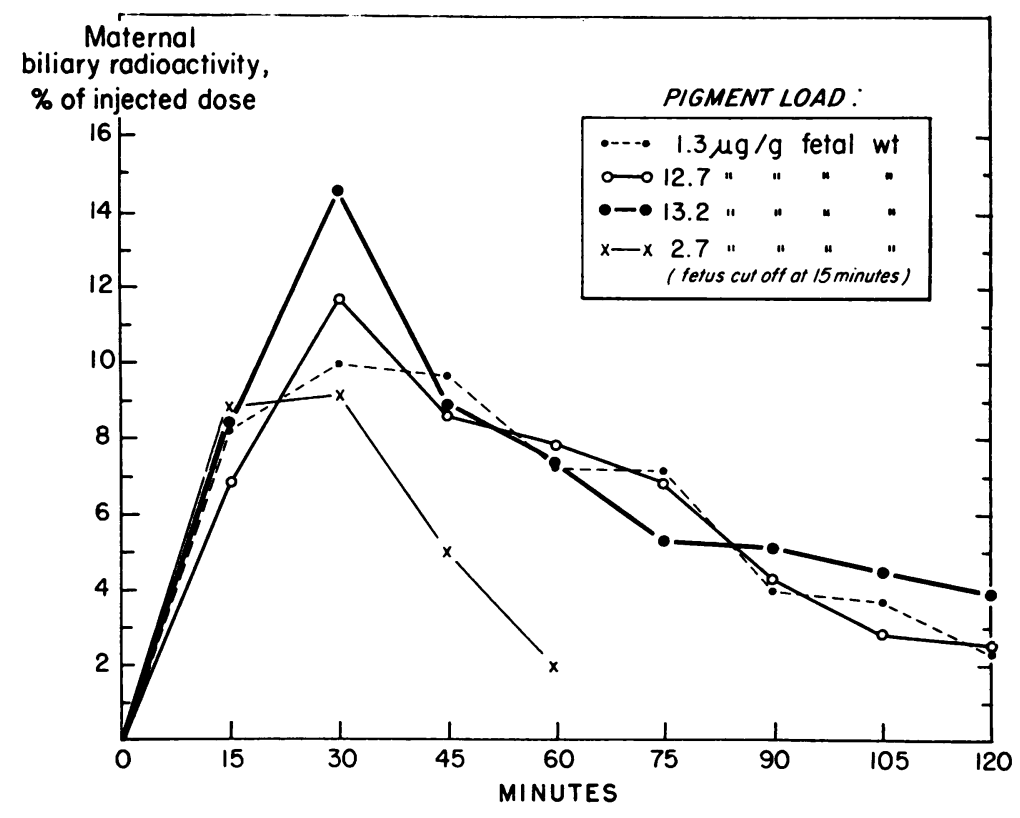

Fig. 2. EXCRETORY RATE OF RADIOACTIVITY IN MATERNAL BILE AFTER ADMiNistration of BILIRUBin-C ${ }^{14}$ To THE FETUS. In one instance, the fetus was removed from the placental circulation 15 minutes after the intrafetal infusion of the pigment.

stances a major portion of the injected label was transferred across the placenta and appeared in the maternal bile, and from 43 to $101 \%$ (mean, $74 \%$ ) of the biliary radioactivity was excreted in the form of conjugated bilirubin. As seen in Figure 2, after administration to the fetus, isotope excretion in maternal bile began within 15 minutes, reached a maximum in 30 minutes, and thereafter gradually decreased. In one instance, when the fetus was removed 15 minutes after infusion of the labeled pigment, thereby interrupting the fetal-placental circulation, the rate of isotope transfer across the placenta fell more rapidly, and the quantity of radioactive label recovered in maternal bile was smaller (Figure 2). Within the range of the pigment loads employed, the percentage of radioactivity transferred across the placenta appeared to be independent of the initial serum pigment concentration in the fetus.

During the 2 hours following intrafetal infusion of unconjugated bilirubin-C ${ }^{14}$, only small amounts of pigment were excreted in the fetal bile, as indicated by recovery of less than $2 \%$ of the injected label from the combined contents of

TABLE II

Recovery of radioactivity in fetal excreta 2 hours after iv injection of unconjugated or conjugated bilirubin- $C^{14}$ through the umbilical vein

\begin{tabular}{|c|c|c|c|c|c|c|c|c|}
\hline \multirow[b]{2}{*}{$\begin{array}{l}\text { Type of pig- } \\
\text { ment given }\end{array}$} & \multirow[b]{2}{*}{$\begin{array}{l}\text { Wt of } \\
\text { fetus }\end{array}$} & & \multicolumn{6}{|c|}{ As per cent of injected dose } \\
\hline & & & $\begin{array}{l}\text { Gall } \\
\text { bladder } \\
\text { content }\end{array}$ & $\begin{array}{l}\text { Gastric } \\
\text { content }\end{array}$ & $\begin{array}{l}\text { Small } \\
\text { bowel }\end{array}$ & $\begin{array}{l}\text { Large } \\
\text { bowel }\end{array}$ & & $\begin{array}{c}\text { Total } \\
\text { biliary } \\
\text { excretion }\end{array}$ \\
\hline & $g$ & & & & & & & \\
\hline Unconjugated & 30.0 & & 0.06 & 0 & 0 & 0 & - & 0.06 \\
\hline Unconjugated & 118.9 & & 0.2 & 0.9 & 0.7 & 0 & & 1.8 \\
\hline Unconjugated & $44.3^{*}$ & i & 0.03 & 0.2 & 0.4 & 0.2 & & 0.8 \\
\hline Conjugated & 36.6 & & 0.03 & 0.5 & 0 & 0 & $=$ & 0.5 \\
\hline Conjugated & 58.4 & & 0.04 & 1.3 & 1.3 & 0.6 & & | 3.2 \\
\hline Conjugated & 89.0 & & 1.6 & 4.4 & 7.5 & 0.6 & 5 & 14.1 \\
\hline
\end{tabular}

* In 40 minutes. 


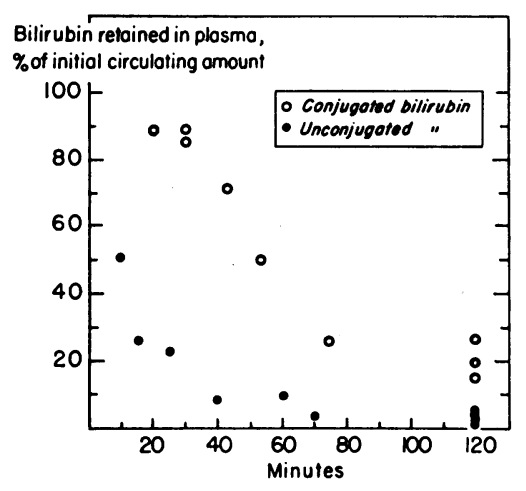

Fig. 3. Disappearance of intravenously injected BILE PIGMENTS FROM THE FETAL CIRCULATION.

the gall bladder and gastrointestinal tract (Table II). At autopsy, fetal brain, kidney and urine, placenta, and maternal plasma failed to reveal significant amounts of the isotope; traces were detectable in fetal perirenal adipose tissue. The fetal liver contained from 4.7 to $21.6 \%$ of the injected radioactivity, and 1.2 to $6.2 \%$ was retained in the fetal plasma.

Infusion of albumin- $I^{131}$ into the fetus. When human or guinea pig albumin- $\mathrm{I}^{131}$ was infused into the fetus, only traces of the labeled protein could be detected in the maternal circulation. Based on a mean maternal plasma volume of $4.2 \%$ of body wt (range, 3.1 to $4.9 \%$ ) as determined with radioiodinated guinea pig albumin, $0.014 \%$ (range, 0.00 to $0.03 \%$ ) of the human albumin- $\mathrm{I}^{131}$ injected into the fetus could be detected in the maternal circulation at the end of 2 hours. Similarly, $0.007 \%$ (range, 0.00 to $0.01 \%$ ) of the administered radioiodinated guinea pig albumin was present in maternal plasma after 1 hour.

When unconjugated bilirubin- $\mathrm{C}^{\mathbf{1 4}}(4.1 \mu \mathrm{g}$ per $\mathrm{g}$ fetal wt) was administered to a fetus together with radioiodinated human albumin, $35 \%$ of the injected labeled pigment was excreted in 1 hour in the form of conjugated bilirubin in the maternal bile, whereas only $0.01 \%$ of the administered albumin- $\mathrm{I}^{131}$ was detected in the maternal plasma. In a similar experiment with labeled pigment and guinea pig albumin- $\mathrm{I}^{131}, 28 \%$ of the bilirubin- $\mathrm{C}^{14}$ appeared in the maternal bile, but less than $0.01 \%$ of the administered radioiodinated albumin was recovered in the maternal circulation.

In sixteen fetuses, the mean plasma volume including the placental circulation was $10.3 \%$ of fetal weight (range, 8.8 to $14.3 \%$ ). The placenta contained $14.4 \%$ (range, 13.2 to $17.2 \%$ ) of the total fetal plasma volume.

Disappearance of unconjugated bilirubin- $C^{14}$ from the fetal circulation. As could be expected from the rapid transfer of the pigment across the placenta, unconjugated bilirubin- $\mathrm{C}^{\mathbf{1 4}}$ was promptly removed from the fetal circulation (Figure 3 ). Thirty minutes after injection, only about $20 \%$ of the administered pigment remained in the fetal plasma, and after 120 minutes, virtually none. After injection of comparable weight-adjusted pigment loads into two adult guinea pigs, the disappearance rate for unconjugated bilirubin was similar to that in the fetal animals with intact placentas.

Intravenous infusion of large amounts of unconjugated bilirubin into maternal guinea pigs resulted in rapid appearance of the pigment in the fetal circulation (Figure 4). Occlusion of the vitelline vessels did not interfere with maternalto-fetal pigment transfer.

Infusion of conjugated bilirubin- $C^{14}$ into the fetus. In contrast to unconjugated pigment, only a minute fraction of the conjugated bilirubin- $\mathrm{C}^{14}$ injected into the fetus was transferred across the placenta and excreted in the maternal bile (Table III). Disappearance of conjugated bilirubin from the fetal plasma was slower than that of unconjugated pigment (Figure 3 ) and probably

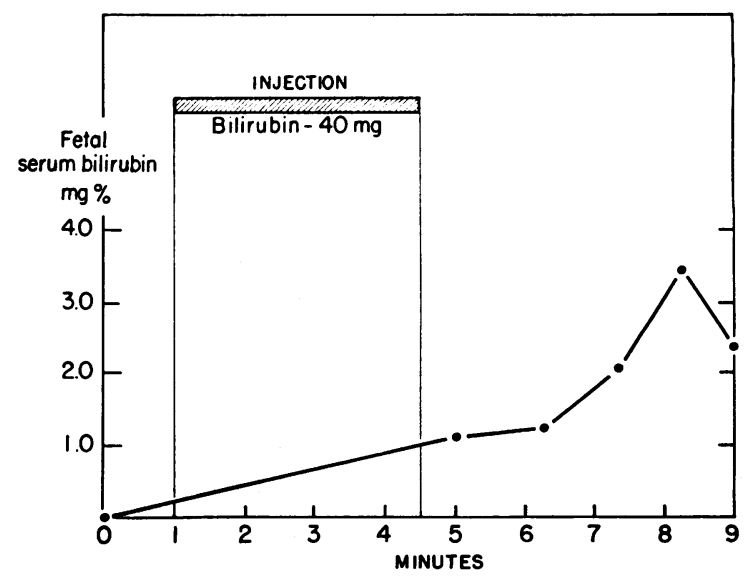

Fig. 4. TRANSFER OF UNCONJUGated BILIRUBin From maternal to fetal circulation. After iv injection of a maternal guinea pig with $40 \mathrm{mg}$ of bilirubin, five individual fetuses were sacrificed at one-minute intervals for determination of fetal serum bilirubin concentration. 
reflected largely distribution into the extravascular compartments. After 30 minutes, $80 \%$, and after 120 minutes, $20 \%$ of the administered pigment load was still in circulation. Moreover, in the course of 2 hours, only 0.5 to $14.1 \%$ of the injected label was excreted in the fetal bile (Table II). Biliary excretion of conjugated bilirubin appeared to be somewhat enhanced in larger and, presumably, more mature fetuses (Table II). In adult guinea pigs, comparable weight-adjusted loads of conjugated bilirubin- $\mathrm{C}^{14}$ were almost completely removed from the circulation in 30 minutes.

Two hours after intrafetal infusion of conjugated bilirubin- $\mathrm{C}^{14}$, no radioactivity could be detected in fetal brain, but traces were present in kidney and in bladder urine, and 11.5 to $36.8 \%$ of the injected dose was recovered in the fetal liver. Histologic examination of the fetal liver showed normal hepatic architecture.

\section{Discussion}

The rate at which a substance diffuses across a biological membrane depends in large measure upon its molecular weight, its charge, and its structure $(23,24)$. As a rule, such membranes are almost impermeable to ionized, lipid-insoluble compounds with molecular weights in excess of 200 , whereas noncharged, lipid-soluble molecules can cross them with relative ease $(23,24)$. The present demonstration of rapid bidirectional transfer of unconjugated bilirubin across the guinea pig placenta is consistent with these concepts. In contrast, the placenta proved to be virtually impermeable to conjugated bilirubin (Table III), which is more polar and has a larger molecular weight. Similar observations have been made in the intestinal tract, where unconjugated, but not conjugated, bilirubin is readily absorbed by the enteric mucosa (21). Moreover, Dancis, Money, Condon, and Levitz (25) have reported that the lipid-soluble estrogen crosses the placenta rapidly in both directions, whereas the more polar estrogen glucuronide is not transferred.

In the plasma, bilirubin is tightly bound to albumin (26), but the latter's rate of exchange between mother and fetus is much slower $(15,16)$ than that of the unconjugated pigment. It is therefore not surprising that on crossing the pla-
TABLE III

Transfer of conjugated bilirubin-C $C^{14}$ across the placenta, as measured by excretion of radioactive bilirubin in maternal bile

\begin{tabular}{ccc}
\hline & $\begin{array}{c}\text { Recovery of radio- } \\
\text { activity in maternal } \\
\text { bile in 2 hours } \\
\text { (expressed as \% of } \\
\text { administered dose) }\end{array}$ \\
\cline { 2 - 3 } $\begin{array}{c}\text { Conjugated } \\
\text { bilirubin-C } \\
\text { given per } \\
\text { fetal wt }\end{array}$ & $\begin{array}{c}\text { In whole } \\
\text { bile }\end{array} \quad \begin{array}{c}\text { In crystal- } \\
\text { lized bilirubin }\end{array}$ \\
$\mu / g$ & & \\
4.5 & 2.2 & 0.3 \\
5.5 & 0.8 & 3.8 \\
13.8 & 5.7 & \\
Mean & 2.9 & \\
\hline
\end{tabular}

cental barrier, the labeled bilirubin changed its attachment from fetal to maternal albumin. This observation suggests that, depending on the prevailing concentration and binding affinity of the albumin on either side of the placenta, bilirubin would tend to equilibrate between fetal and maternal plasma, were it not that the maternal circulation is being continuously cleared of pigment by the liver. A transplacental gradient, favoring transfer of pigment from the fetal to the maternal side, is thereby maintained, which in all probability accounts for the rapid disappearance of the injected bilirubin- $\mathrm{C}^{14}$ from the fetal circulation (Figure 3) and for its excretion in the maternal bile (Table I).

Since the enzymatic mechanism for glucuronide formation is deficient in fetal guinea pig liver (6), it was to be expected that only a minute fraction of the injected bilirubin- $\mathrm{C}^{14}$ would be excreted in the fetal bile (Table II). Although this impairment in fetal pigment excretion has previously been attributed solely to the defective conjugating apparatus (27), our findings suggest the coexistence of a hepatic excretory defect. As Table II illustrates, fetal biliary excretion of injected conjugated bilirubin- $\mathrm{C}^{14}$ differed little from that of the unconjugated pigment, indicating that even if the fetal liver were able to form the conjugate, its biliary excretion could not be accomplished efficiently. Since transplacental elimination is barred for conjugated bilirubin (Table III), its rate of disappearance from the fetal circulation was slower than that of the unconjugated pigment (Figure 3 ). It is tempting to speculate that in the fetus the delayed maturation of the 
microsomal conjugating apparatus may represent a protective device permitting disposition of the fetal unconjugated bilirubin across the placenta. The reduced excretory function of the fetal liver is not limited to bile pigments but extends to other compounds, as demonstrated by a similar excretory defect for Bromsulphalein in chick embryos (28) and in fetal guinea pigs (29).

Recently, Grodsky has reported that in the rat, significant transfer of bilirubin from the fetal to the maternal side did not seem to occur (30); this may be due to actual species differences. However, since these experiments were carried out with tritiated bilirubin, which appears to permit exchange of its label with hydrogen of the serum proteins (31), the failure to detect significant isotope excretion in the maternal bile may have been due to methodologic difficulties.

Because of anatomical differences between the primate and guinea pig placentas (32), direct application of the present findings to human physiology may appear premature. Concurrent studies with bilirubin- $\mathrm{C}^{14}$ in pregnant monkeys (33) are, however, in agreement with the present findings in guinea pigs, indicating that unconjugated bilirubin can be rapidly transferred across the primate placenta. This suggests that in man the placenta may assume a similar transfer function for fetal bilirubin, which could account for the low pigment levels in cord blood. Moreover, the coexistence in the fetal liver of defects in the conjugating and the excretory apparatus may provide a plausible explanation for the so-called inspissated bile syndrome observed in erythroblastotic infants (34). Although the maturation rate of these two hepatic functions in the newborn is not known, it is possible that during the neonatal period, the liver's capacity to conjugate may temporarily exceed its excretory ability. With the excessive pigment loads occurring in erythroblastosis, this may result in a transient rise in conjugated bilirubin, complicating the severe hemolytic hyperbilirubinemia.

\section{Summary}

1. A technique is described for delivery of viable guinea pig fetuses with intact placental circulation. This experimental model was used to determine the permeability of the placenta for unconjugated and conjugated bilirubin- $\mathrm{C}^{14}$ injected into the fetal circulation.

2. Unconjugated bilirubin-C ${ }^{14}$ rapidly disappeared from the fetal plasma, and 52 to $66 \%$ of the administered radioactivity was excreted in the maternal bile within 2 hours. By contrast, disappearance of conjugated bilirubin- $\mathrm{C}^{14}$ was slower, and less than $4 \%$ of the injected pigment dose appeared in the maternal bile.

3. On simultaneous administration of unconjugated bilirubin- $\mathrm{C}^{14}$ and albumin- $\mathrm{I}^{131}$ to the fetus, only the pigment was transferred across the placenta, whereas virtually no labeled albumin was detectable in the maternal circulation.

4. In the fetus, biliary excretion of unconjugated and conjugated bilirubin- $\mathrm{C}^{14}$ was impaired to a similar degree, suggesting that, in addition to deficient conjugation, the fetal liver also exhibits an excretory defect.

\section{References}

1. Schenker, S., N. H. Dawber, and R. Schmid. Disposition of bilirubin in the fetus (abstract). J. Lab. clin. Med. 1962, 60, 1015.

2. Fashena, G. J. Mechanism of hyperbilirubinemia in the newborn infant. Experimental demonstration of functional hepatic immaturity. Amer. J. Dis. Child. 1948, 76, 196.

3. Son Vahlquist, Bo C. Das Serumeisen. Eine Pädiatrisch-Klinische und Experimentelle Studie. Acta Paediat. (Uppsala) Suppl. V, 1941, 28, 172.

4. Schenker, S., and R. Schmid. Unpublished observations.

5. Brown, A. K., and H. S. McGaughey, Jr. Observations on maternal, fetal and placental bilirubin concentrations at the time of delivery. Amer. J. Dis. Child. (abstract). 1960, 100, 574.

6. Brown, A. K., and W. Zuelzer. Studies on the neonatal development of glucuronide conjugating system. J. clin. Invest. 1958, 37, 332.

7. Lathe, G. H., and M. Walker. An enzyme defect in human neonatal jaundice and in Gunn's strain of jaundiced rats (abstract). Biochem. J. 1957, 67, $9 \mathrm{P}$.

8. Davidson, L. T., K. K. Merritt, and A. A. Weech. Hyperbilirubinemia in the newborn. Amer. J. Dis. Child. 1941, 61, 958.

9. Mollison, P. L., and M. Cutbush. A method of measuring the severity of a series of cases of hemolytic disease of the newborn. Blood 1951, 6, 777.

10. Schmid, R., S. Buckingham, G. A. Mendilla, and L. Hammaker. Bilirubin metabolism in the fœtus. Nature (Lond.) 1959, 183, 1823.

11. Cserna, S., and S. Liebman. Beitrag zur Lehre des Ikterus Neonatorum. Klin. Wschr. 1923, 2, 2122. 
12. Findley, L., G. Higgins, and M. W. Stanier. Icterus neonatorum: its incidence and cause. Arch. Dis. Childh. 1947, 22, 65.

13. Döring, G. K. Úber die Durchlässigkeit der Plazenta für Bilirubin. Geburtsh. u. Frauenheilk. 1958, 18, 360.

14. Ostrow, J. D., L. Hammaker, and R. Schmid. The preparation of crystalline bilirubin- $\mathrm{C}^{14}$. J. clin. Invest. 1961, 40, 1442.

15. Dancis, J., and M. Shafran. The origin of plasma proteins in the guinea pig fetus. J. clin. Invest. 1958, 37, 1093.

16. Bangham, D. R., K. R. Hobbs, and D. E. H. Tee. Transmission of serum proteins from fœtus to mother in the rhesus monkey. Indwelling cannulation of fœtus without interruption of pregnancy. Lancet 1960, 2, 1173.

17. Malloy, H. T., and K. A. Evelyn. The determination of bilirubin with the photoelectric colorimeter. J. biol. Chem. 1937, 119, 481.

18. Arey, L. B. Developmental Anatomy, 6th ed. Philadelphia, W. B. Saunders, 1954, pp. 107-113.

19. Cohn, E. J., L. E. Strong, W. L. Hughes, Jr., D. J. Mulford, J. N. Ashworth, M. Melin, and M. L. Taylor. Preparation and properties of serum and plasma proteins. IV. A system for the separation into fractions of the protein and lipoprotein components of biological tissues and fluids. J. Amer. chem. Soc. 1946, 68, 459.

20. Beierwaltes, W. H., P. C. Johnson, and A. J. Solari. Clinical Use of Radioisotopes. Philadelphia, W. B. Saunders, 1957, pp. 195-203.

21. Lester, R., and R. Schmid. Intestinal absorption of bile pigments. I. The enterohepatic circulation of bilirubin in the rat. J. clin. Invest. 1963, 42, 736.

22. Snedecor, G. W. Statistical Methods, 4th ed. Ames, Iowa, Iowa State College, 1946.
23. Wilson, T. H. Intestinal Absorption. Philadelphia, W. B. Saunders, 1962, pp. 40-68.

24. Schanker, L. S. Passage of drugs across body membranes. Pharmacol. Rev. 1962, 14, 501.

25. Dancis, J., W. L. Money, G. P. Condon, and M. Levitz. The relative transfer of estrogens and their glucuronides across the placenta in the guinea pig. J. clin. Invest. 1958, 37, 1373.

26. Ostrow, J. D., and R. Schmid. The protein-binding of $\mathrm{C}^{14}$-bilirubin in human and murine serum. $\mathrm{J}$. clin. Invest. 1963, 42, 1286.

27. Billing, B. H., P. G. Cole, and G. H. Lathe. Increased plasma bilirubin in newborn infants in relation to birth weight. Brit. med. J. 1954, 2, 1263.

28. Brauer, R. W., L. M. Julian, and T. S. Krebs. Maturation of liver function in the chick embryo as explored with $S^{35}$-sulfobromophthalein. Ann. N. Y. Acad. Sci. 1963, in press.

29. Schenker, S., J. Goldstein, and B. Combes. Unpublished observations.

30. Grodsky, G. M. Aspects of the metabolism of bromsulfalein and bilirubin in Perinatal Pharmacology, Report of the 41st Ross Conference on Pediatric Research, C. D. May, Ed. Columbus, Ross Laboratories, 1962, p. 68.

31. Grodsky, G. M., J. V. Carbone, R. Fanska, and C. T. Peng. Tritiated bilirubin: preparation and physiological studies. Amer. J. Physiol. 1962, 203, 532.

32. Amoroso, E. C. Placentation in Marshall's Physiology of Reproduction, 3rd ed., A. S. Parkes, Ed. London, Longmans' Green, 1952, vol. 2, pp. 127-311.

33. Lester, R., R. E. Behrman, and J. F. Lucey. Transfer of bilirubin- $\mathrm{C}^{14}$ across monkey placenta. Pediatrics 1963, 32, 416.

34. Harris, L. E., F. J. Farrell, R. G. Shorter, E. A. Banner, and D. R. Mathieson. Conjugated serum bilirubin in erythroblastosis fetalis: an analysis of 38 cases. Proc. Mayo Clin. 1962, 37, 574. 